\title{
Critical Health Literacy and Doctor-Patient Communication: Highlighting the Role of Patients' Support Networks in Chronic Conditions
}

\author{
Dennis Butto*, ***, Hellen Mberia*, Julius Bosire*** \\ *School of communication and Development Studies, Jomo Kenyatta University of Agriculture and Technology, \\ P. O. Box 62000-00200 Nairobi, Kenya. \\ **2Technical University of Kenya, P.O. Box 52428 - 00200, Nairobi- Kenya \\ ***School of Health Sciences, Kirinyaga University, P.O Box 143 - 10300, Kerugoya Kenya \\ Correspondence should be addressed to Dennis Butto; dbutto@kyu.ac.ke \\ DOI: 10.29322/IJSRP.10.12.2020.p10820 \\ http://dx.doi.org/10.29322/IJSRP.10.12.2020.p10820
}

\begin{abstract}
Health literacy is a set of individual skills that allow a person to gain and utilize new health information. It incorporates the ability to understand health information from pamphlets, obtain applicable health information during an interview with health experts, and to access and assess health information from other platforms. Patients with inadequate critical health literacy have a poorer understanding of their disease progression, medication regimens, and techniques for dealing with their disease. This study was carried out to establish the influence of critical health literacy in doctor-patient communication among HIV/AIDS patients in Homa Bay county, Kenya. The results showed that $51 \%$ of the 362 participants involved in the study were females, and the majority (30.9\%) of respondents fell in the age group of 45 years and above. The level of critical health literacy among the study participants was adequate at a mean of 3.515 and Standard Deviation (SD) of 1.186. Critical Functional health literacy also had a significant positive influence on doctor patient communication among the study participants (Nagelkerke $\mathrm{R}$ square $=0.318$ ). Critical health literacy is acquired mainly through empowerment-based capabilities, where members become enlightened on issues, take part in important dialogue, and take an interest in decision making for the sake of their health. Therefore, encouraging people living with HIV/AIDS to form or join existing networks and support groups is highly recommended. This will create more avenue for patients, acting as an individual or in a group to improve health.
\end{abstract}

Key words: Critical Heath literacy, Homa Bay, Doctor-patient communication, HIV/AIDS

\subsection{Introduction}

Studies show that many adults have challenges with health literacy. For example, in the United States of America, approximately $45 \%$ of the adult population has health literacy skills below satisfactory. Although fewer European studies on the topic have been conducted, a recent report about eight European Union member states indicated comparable figures; $47 \%$ has inadequate health literacy. In the Netherlands, $25 \%$ of the population does not have adequate health literacy (1).

Populations in all likelihood to experience low health literacy are older adults, racial and ethnic minorities, individuals with less than a high school training, people with inadequate income, non-native speakers of English, and people with poor health status (2). Education, language, lifestyle, access to assets, and age are all factors that have effects on someone's health literacy skills. Health literacy consists of numeracy skills, for example, calculating cholesterol and blood sugar levels, measuring medications, and knowledge of nutrition labels all require math abilities (3). Contrasted with those having good health literacy, patients with limited health literacy experience challenges in health and healthcare access. They have a poorer understanding of their disease progression, medication regimens, and techniques for dealing with their disease. Limited health literacy can also lessen the effectiveness of health services offered, thereby contributing to poorer health outcomes such as higher incidence of hospitalization and infrequent utilization of preventive services, both of which are associated with higher healthcare costs $(4$

Nutbean (5) describes critical health literacy as very advanced cognitive abilities that, in combination with social skills, can 
be utilized to examine information critically and to use this information to gain greater control over life occasions and circumstances. Taken literally, the 'critical' aspect of critical health literacy may be described as a higher-level cognitive capability as recommended by McLaughlin and DeVoogd (6). If health literacy is the capability to access, comprehend, appraise and apply health information, then critical health literacy is a higher-order process that may be created through training to critically assess the information of significance to health (7).

Critical health literacy has additionally been defined as empowerment in which being critically health literate might imply acting as a person or in a group to improve health through the political framework or social activism (8). Just like health literacy may be portrayed as 'new wine into old bottles' of empowerment so critical health literacy, with its focus on community capacity to take action on social and economic determinants of health, is a critical element for community development (9). Taking critical health literacy from this point of view and borrowing from Freire, critical health literacy is, like community growth, a process where in members become enlightened on issues, take part in the important dialogue, and take an interest in decision making for the sake of their health (10).

Even though the seventh Global Conference on Health Promotion (11) recognized improving health literacy as a method for fostering community engagement and empowerment, critical health literacy might be viewed as the overlooked area of health literacy, hardly receiving any focus or engagements which can significantly contribute towards this outcome. Some people contend that minimal consideration given to the psychological constructs in the definition of critical health literacy may lead to health literacy taking a rather cognitive focus and that health outcomes are much more likely to be achieved while the dichotomy between knowledge and psychological constructs become less pronounced (12). Critical health literacy may provide a chance to overcome the above challenge. The absence of consideration the concept has been given might be because of a lack of conceptual models and frameworks investigating critical health literacy (13). On the other hand, it might be the aftereffect of difficulties and confusion in understanding what exactly empowerment-based capabilities include and in what ways the concept can be improved (14). While such confusion may exist, this concept's role in improving health outcomes cannot be overlooked.

\subsection{Methods}

\subsection{Study design}

This study utilized a cross-sectional, quantitative survey

This publication is licensed under Creative Commons Attribution CC BY. http://dx.doi.org/10.29322/IJSRP.10.12.2020.p10820 design conducted among 384 HIV/AIDS patients in Homa Bay county.

\subsection{Sampling technique}

A stratified random sampling method was applied to select the respondents in the eight hospitals in Homa county or the eight strata for this study as shown in the table 1 below.

TABLE 1: Strata and sampling intervals for the study

\begin{tabular}{llll}
\hline Hospital & $\begin{array}{l}\text { Clients } \\
\text { population }\end{array}$ & $\begin{array}{l}\text { Stratified } \\
\text { sample }\end{array}$ & $\begin{array}{l}\text { Sampling } \\
\text { Interval }\end{array}$ \\
\hline $\begin{array}{l}\text { Homa Bay } \\
\begin{array}{l}\text { County } \\
\text { Referral }\end{array}\end{array}$ & 7214 & 166 & 43 \\
$\begin{array}{l}\text { Mbita sub } \\
\text { county }\end{array}$ & 3226 & 74 & 44 \\
$\begin{array}{l}\text { Suba sub } \\
\text { county }\end{array}$ & 2232 & 54 & 41 \\
$\begin{array}{l}\text { Rangwe sub } \\
\text { county }\end{array}$ & 554 & 13 & 43 \\
$\begin{array}{l}\text { Ndhiwa sub } \\
\text { county }\end{array}$ & 328 & 8 & 41 \\
$\begin{array}{l}\text { Karachuonyo } \\
\text { sub county }\end{array}$ & 873 & 20 & 44 \\
$\begin{array}{l}\text { Kasipul sub } \\
\text { county }\end{array}$ & 975 & 26 & 38 \\
$\begin{array}{l}\text { Kabondo sub } \\
\text { county }\end{array}$ & 1223 & 27 & 45 \\
Total & $\mathbf{1 6 , 6 2 5}$ & $\mathbf{3 8 4}$ & \\
\hline
\end{tabular}

\subsection{Data collection instrument}

This study used of a structured self-administered questionnaire to obtain data from the respondents. Fifteen questions adapted from the Consumer Assessment of Healthcare Providers and Systems (CAHPS) health literacy item set was used. The CAHPS health literacy item set is a validated tool developed to assess provider communication about medicines, tests, and medical conditions. The study adopted the five response categories standard for CAHPS ("never," "rarely," "occasionally," 'regularly' and "always"). For all but 2 of the CAHPS questions, "always" represented the most positive response, but for the questions that asked about providers using medical jargon and speaking too fast, the "never" response was the most favorable. Thus, the coding for this question was reversed in order to be consistent with the other CAHPS questions. A weighted mean score was calculated for each CAHPS survey collected, with possible scores ranging from 1(lowest rating of provider communication) to 5 (highest possible provider communication rating). Critical Health literacy on the other hand was measured using four items Likert scales adopted from Ishikawa, Takeuchi \& Yano (15). 


\subsection{Data collection procedure}

The prospective respondents were obtained from the sampling frame and sampled using the sampling intervals, as shown in Table 2.1 above, randomly starting from the first name on the list. The clinic appointment dates for selected patients were then noted, and clients approached at the registration department of the clinic where their consent was sought and questionnaires issued to those who consented. The questionnaires were picked from respondents after they had completed the treatment process. This process was repeated until the 384 questionnaires were distributed. At the end only 362 were fully filled up and included in the final analysis giving a response rate of $94 \%$.

\subsection{Validity and reliability of study instrument}

Thirty (30) participants drawn from HIV/AIDS patients in the neighboring Migori County were participated in the pilot study. Additionally, factor analysis and Cronbach's Alpha test, were used to determine the validity and reliability of the study instrument respectively. The alpha coefficient for variables constituting doctor patient communications was found to be

\subsection{Results and Discussion}

\subsection{Demographic characteristics of the study participants}

The respondents' demographic characteristics included; age, gender, marital status, and education level. The respondents
0728 the recommended threshold of 0.7. Further, all the items for measuring doctor patient communications had factor loadings raging between 0.653 and 0.768 making them valid to measure the respective variables of the study.

\subsection{Ethical consideration}

The researchers obtained permit from the National Commission for Science, Technology, and Innovation- Kenya. In Homa Bay county, the county director for health and the chief executive officer, Homa Bay County Teaching and Referral Hospital, granted the study's authority. Informed consent was obtained from each participant. All participants were assured of anonymity and confidentiality and were informed of the purpose, the procedures, risk, benefits, and voluntary participation. This information was reinforced with an informed consent form whose content was verbally presented to each participant. No personal identifying information was included in the tool or report to ensure further confidentiality, and participants were informed that their involvement or lack of it would not affect their care at the clinic.

were also asked to state the year they were first diagnosed with HIV infection from which illness duration was calculated. The results are illustrated in Table 2 below

TABLE 2: Patients demographic characteristics and effectiveness of doctor patient communication

\begin{tabular}{ccc}
\hline $\begin{array}{c}\text { Demographic Factors } \\
\mathbf{n = 3 6 2}\end{array}$ & Frequency & \% Percentage \\
\hline & Age of the respondents & \\
18-24 years & 57 & 15.7 \\
$25-31$ years & 67 & 18.5 \\
$32-38$ years & 54 & 14.9 \\
39-45 years & 72 & 19.9 \\
Above 45 years & $\mathbf{1 1 2}$ & $\mathbf{3 0 . 9}$ \\
Total & 362 & 100.0 \\
& Marital status \\
Married & $\mathbf{1 8 9}$ & $\mathbf{5 2 . 2}$ \\
Divorced & 29 & 8.0 \\
Widowed & 54 & 14.9 \\
Single & 90 & 24.9 \\
Total & 362 & 100.0
\end{tabular}

This publication is licensed under Creative Commons Attribution CC BY. 


\section{Level of education}

$\begin{array}{ccc}\text { Class } 8 \text { or less } & 100 & 27.6 \\ \text { Some High School } & \mathbf{1 1 8} & \mathbf{3 2 . 6} \\ \text { High school completed } & 93 & 25.7 \\ \text { College/University } & 51 & 14.1 \\ \text { Total } & 362 & 100.0 \\ & \text { Duration of HIV infection } & \\ \text { 0-5 years } & 67 & 18.5 \\ \text { 6-10 years } & \mathbf{1 0 7} & \mathbf{2 9 . 6} \\ \text { 11-15 years } & 91 & 25.1 \\ \text { 16-20 years } & 71 & 19.6 \\ 21 \text { years and above } & 26 & 7.2 \\ \text { Total } & 362 & 100.0\end{array}$

The respondents' age distribution was between 18 years and 69 years, with the majority $(31 \%)$ aged above 45 years followed by $25-31$ years $(21 \%)$, while young people aged between 18-24 years made up $16 \%$ of the respondents as illustrated in Table 2 above. Regarding the respondent's marital status, the majority (52\%) were married, $25 \%$ single, while $15 \%$ and $8 \%$ were widowed and divorced, respectively. The respondents were asked to state the gender with which they identify themselves, and the option of male, female, or others was given. 184 accounting for $51.05 \%$, were female while 48.69 were male, and a further $0.26 \%$ choose 'others' without giving further details, as illustrated in table 2 above. The above results illustrate that there was almost parity in terms of the gender of the respondents, even though the female gender was a slight majority. This is in agreement with the previous studies on HIV/AIDS prevalence in Homa Bay county where women had significantly higher HIV prevalence than men at $6.9 \%$ compared to $4.4 \% ; P<0.0001(12,13)$. These results contrasted other previous studies that found HIV prevalence to be highest among persons who had been widowed or formally married, separated, or divorced probably due to the loss of the absent spouse to HIV/AIDS (14). The finding herein gives hope that with good adherence to HIV/AIDS lifesaving drugs and good self-management skills, a patient can live normally if their partner died of HIV/AIDS. As shown in Table 2 above, $57 \%$ of the respondents had postprimary school education, even though $31 \%$ of this did not finish high school. $28 \%$ were educated up to class eight, while a further $14 \%$ were college or university graduates. Table 2 above shows that the majority (30\%) of the respondents were those who had been having HIV/AIDS infection for between 6-10 years, followed by $25 \%$ who had been with the infection for between 11-15years while 19\% and 7\% had had the infection for between $0-5$ years and 21 years above, respectively. The fact that over $50 \%$ of respondents had lived with HIV infection for more than ten years could be a pointer to the efficacy of preventive and supportive measures put in place by the government.

\subsection{Critical Health Literacy}

Table 3: Distribution of respondents by responses to critical health literacy items

\begin{tabular}{clllllll}
\hline $\begin{array}{c}\text { Critical Health Literacy } \\
\text { Items } \\
\text { N=362 }\end{array}$ & Never & Rarely & Occasionally & Regularly & Always. & Mean & SD \\
\hline \multicolumn{1}{c}{$\begin{array}{l}\text { Since being diagnosed } \\
\text { with HIV, how often } \\
\text { have you considered } \\
\text { whether the }\end{array}$} & $7.2 \%$ & $17.1 \%$ & $35.1 \%$ & $22.1 \%$ & $18.5 \%$ & $\mathbf{3 . 2 8}$ & $\mathbf{1 . 1 6 1}$ \\
information given to \\
by healthcare provider \\
is applicable to your \\
situation?
\end{tabular}

This publication is licensed under Creative Commons Attribution CC BY. 
with HIV, how often

2 have you considered the credibility of the information given to you by your doctor?

Since being diagnosed 3 with HIV, how often have you checked whether the information given by your doctor was valid and/or reliable?

Since being diagnosed

4 with HIV, how often have you collected information to make health-related decisions $\begin{array}{lllllll}5.2 \% & 16.6 \% & 28.5 \% & 25.7 \% & 24.0 \% & \mathbf{3 . 4 7} & \mathbf{1 . 1 7 5}\end{array}$

$\begin{array}{lllllll}7.2 \% & 12.2 \% & 20.4 \% & 29.0 \% & 31.2 \% & \mathbf{3 . 6 5} & \mathbf{1 . 2 3 7}\end{array}$

Cumulative mean

$3.515 \quad 1.186$

Nutbean (5) described critical health literacy as more advanced cognitive skills that, together with social skills, can be applied to critically analyze health information and use this information to exert greater control over life events and situations. Critical health literacy was similarly measured using the scale adopted from Ishikawa, Takeuchi, \& Yano (15). Each item was rated on a 5-point scale, ranging from 1, 'never' to 5, 'always,' with always denoting a higher degree of health literacy. Critical health literacy was then categorized into either inadequate or adequate for scores between 1 to 3.4 and 3.5 to 5 , respectively.

As shown in Table 4.13 above, critical health literacy among HIV/AIDS patients in Homa Bay county was adequate, with a mean score of 3.515 and a standard deviation of 1.186. Liu et al. (8)noted that critical health literacy implies acting as a person or in a group to improve health through the political framework or social activism. Therefore, critical health literacy focuses on community capacity to take action on social and economic determinants of health (9). The adequate level of health literacy in Homa bay county might be due to numerous NGOs and civil society organizations conducting health promotion activities in the country. According to the National Aids Control Council (16), Homa Bay county has about 24 implementing partners fighting the HIV/AIDS pandemic. Through Community Health Strategy implementation, the partners have reached households with health information through community health workers and other community-based organizations.

This study's results further show that over $40 \%$ of respondents regularly considered the applicability of healthcare providers' information to their disease situation. A further $51 \%$ had considered the credibility of such information given to them by their doctors. Additionally, over half of the respondents reported that they always go a step further to check the validity/reliability of the information given by doctors regularly. Since being diagnosed with HIV, for example, most of the respondents (64\%) in this study have tried to collect information to make health-related decisions, which could be a pointer to the level of social empowerment that these respondents have.

To a large extent, our findings have contradicted findings from other studies conducted in the area of critical health literacy. In the European Health Literacy Survey (17) respondents reported that items reflecting critical health literacy, including judging health information's credibility, are most difficult. Heijmans et al. (17) and Harris et al. (18) similarly found respondents in their studies scoring poorly in the critical health literacy scales. These studies, however, focused mainly on diabetes and not on HIV/AIDS. 


\subsection{Doctor Patient communication}

TABLE 4: Distribution of respondents by perception of doctor patient communication

\begin{tabular}{|c|c|c|c|c|c|c|c|}
\hline $\begin{array}{c}\text { Doctor Patient } \\
\text { Communication (DPC) } \\
\text { Items } \\
\mathbf{N}=362\end{array}$ & Never & Rarely & Occasionally & Regularly & Always. & Mean & SD \\
\hline $\begin{array}{l}\text { How often does your doctor } \\
\text { listen carefully to you? }\end{array}$ & $6.1 \%$ & $11.3 \%$ & $35.1 \%$ & $19.9 \%$ & $27.6 \%$ & 3.52 & 1.182 \\
\hline $\begin{array}{l}\text { How often does your doctor } \\
\text { explain your health } \\
\text { concerns in a way that is } \\
\text { easy to understand? }\end{array}$ & $2.8 \%$ & $14.6 \%$ & $24.9 \%$ & $24.6 \%$ & $33.1 \%$ & 3.71 & 1.154 \\
\hline $\begin{array}{l}\text { How often does your doctor } \\
\text { give you easy to understand } \\
\text { instructions about taking } \\
\text { care of your health } \\
\text { problems? }\end{array}$ & $4.1 \%$ & $11.6 \%$ & $21.8 \%$ & $32.0 \%$ & $30.4 \%$ & 3.73 & 1.136 \\
\hline $\begin{array}{l}\text { How often does your doctor } \\
\text { seem to know the important } \\
\text { information about your } \\
\text { health problems? }\end{array}$ & $3.3 \%$ & $9.7 \%$ & $23.5 \%$ & $30.1 \%$ & $33.4 \%$ & 3.81 & 1.105 \\
\hline $\begin{array}{l}\text { How often does your doctor } \\
\text { show respect for what you } \\
\text { tell him/her? }\end{array}$ & $2.2 \%$ & $10.8 \%$ & $23.8 \%$ & $24.6 \%$ & $38.7 \%$ & 3.87 & 1.114 \\
\hline $\begin{array}{l}\text { How often does your doctor } \\
\text { spend enough time with } \\
\text { you? }\end{array}$ & $3.9 \%$ & $7.5 \%$ & $19.6 \%$ & $29.3 \%$ & $39.8 \%$ & 3.94 & 1.113 \\
\hline $\begin{array}{l}\text { How often does your doctor } \\
\text { use medical words that you } \\
\text { do not understand? }\end{array}$ & $16.9 \%$ & $20.4 \%$ & $35.6 \%$ & $18.8 \%$ & $8.3 \%$ & 3.19 & 1.169 \\
\hline $\begin{array}{l}\text { How often does your doctor } \\
\text { talk too fast when talking } \\
\text { with you? }\end{array}$ & $16.3 \%$ & $22.4 \%$ & $26.8 \%$ & $22.1 \%$ & $12.4 \%$ & 3.08 & 1.262 \\
\hline $\begin{array}{l}\text { How often does your doctor } \\
\text { use pictures or drawings or } \\
\text { models to explain issues to }\end{array}$ & $11.6 \%$ & $18.0 \%$ & $28.7 \%$ & $24.6 \%$ & $17.1 \%$ & 3.18 & 1.244 \\
\hline
\end{tabular}




\begin{tabular}{|c|c|c|c|c|c|c|c|}
\hline $\begin{array}{l}\text { How often does your doctor } \\
\text { give you easy to understand } \\
\text { instructions about how to } \\
\text { take your medicines? }\end{array}$ & $2.5 \%$ & $11.0 \%$ & $24.6 \%$ & $25.4 \%$ & $36.5 \%$ & 3.82 & 1.117 \\
\hline $\begin{array}{l}\text { How often does your doctor } \\
\text { explain the possible side } \\
\text { effects of your medicines? }\end{array}$ & $2.5 \%$ & $12.4 \%$ & $31.2 \%$ & $20.2 \%$ & $33.7 \%$ & 3.7 & 1.133 \\
\hline $\begin{array}{l}\text { How often does your doctor } \\
\text { explain medication side } \\
\text { effects in a way that is easy } \\
\text { to understand? }\end{array}$ & $4.7 \%$ & $8.8 \%$ & $32.3 \%$ & $24.9 \%$ & $29.3 \%$ & 3.65 & 1.129 \\
\hline $\begin{array}{l}\text { How often does your doctor } \\
\text { suggest ways to help you } \\
\text { remember to take your } \\
\text { medicines? }\end{array}$ & $4.7 \%$ & $8.8 \%$ & $32.3 \%$ & $24.9 \%$ & $29.3 \%$ & 3.6 & 1.169 \\
\hline $\begin{array}{l}\text { How often does your doctor } \\
\text { explain the results of your } \\
\text { blood test, X-ray, or other } \\
\text { laboratory tests in a way } \\
\text { that is easy to understand? }\end{array}$ & $5.8 \%$ & $16.6 \%$ & $31.5 \%$ & $21.8 \%$ & $24.3 \%$ & 3.42 & 1.189 \\
\hline $\begin{array}{l}\text { How often do you feel that } \\
\text { your doctor cares about you } \\
\text { as a person? }\end{array}$ & $5.0 \%$ & $11.9 \%$ & $19.3 \%$ & $20.7 \%$ & $43.1 \%$ & 3.85 & 1.237 \\
\hline \multicolumn{6}{|c|}{ Cumulative mean/SD } & 3.60 & 1.164 \\
\hline
\end{tabular}

To measure the quality of doctor-patient communication, fifteen questions adapted from the Consumer Assessment of Healthcare Providers and Systems (CAHPS) health literacy item set were used. A five response category comprising 'Never,' 'Rarely,' 'Occasionally,' 'Regularly' and 'Always' was utilized. For all but two of the CAHPS items, "always" represented the most positive response, but for the questions asking about health providers using medical jargon and speaking too fast, the "never" response represented the highest approval from the patients. Therefore, the coding for these questions was reversed to be consistent with the other CAHPS items. A total weighted mean score was calculated for each CAHPS survey collected, with possible mean scores ranging from 1-5, representing the lowest rating provider communication and the highest possible provider communication rating, respectively. Consequently, mean scores below 3.5 were graded as non- effective, while scores ranging between 3.5 to 5 were graded effectively.

This publication is licensed under Creative Commons Attribution CC BY. http://dx.doi.org/10.29322/IJSRP.10.12.2020.p10820
Table 4 above illustrates that the patients surveyed rated the quality of their provider's communication as effective with a mean score of 3.60 and a standard deviation of 1.164 . Effective communication from providers may compensate for a lack of understanding with patients with inadequate health literacy in clinical settings. Burch \& Jackson [19] noted that in the recent past, the average number of clinical items, ranging from diagnoses, medications to diagnostic tests addressed at adult primary care visits, has increased from 5 to 7 , while the time spent on each item has decreased from 4.4 to 3.8 minutes. This underscores how effective communication can be an important tool, especially in resource constraint settings.

\subsection{Critical health literacy and doctor patient communication among HIV/AIDS Patients}

Simple logistic regression was carried to establish the level to which critical health literacy influences doctor patient communication among HIV/AIDS patients in Homa Bay 
ISSN 2250-3153

County, Kenya. Before conducting logistic regression analysis, data for doctor patient communication was transformed into a binary form assuming 0 and 1 values to mean non- effective and effective, respectively. The overall effectiveness of the dependent variable was measured using the fifteen items on the questionnaire. To classify the dependent variable (Doctor Patient communication, DCP) as effective or non-effective, the weighted scale of the indicator variables forming the dependent variables was computed as follows: -

$$
\mathrm{Y}=\frac{D C P 1(1)+D C P 2(2)+\cdots+D C P 15(15)}{1+2+\cdots+15}
$$

$\mathrm{Y}$ (doctor patient communication among HIV/AIDS patients) was a continuous random variable with values lying between $0-5$. The $\mathrm{Y}$ values were further transformed into two categories with values of lying between 1-3.4 were categorized as non-effective while any value of $\mathrm{Y}$ lying between 3.5-5.0 was categorized as effective. From the above description, new Y values were corded as effective (1) and non-effective (0), respectively, before conducting logistic regression.

The logistic regression between critical health literacy and doctor patient communication was performed. Table 5 below illustrates the findings for Block 0, which demonstrated that majority of the respondents were in the opinion that doctor patient communication among HIV/AIDS patients in Homa Bay county was effective.

\section{Block 0: Beginning Block}

Table 5: Classification Table 1 for Critical health literacy

\begin{tabular}{|c|c|c|c|c|c|}
\hline \multirow[t]{3}{*}{ 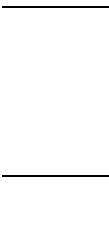 } & \multirow[t]{3}{*}{ Observed } & & & Predicted & \multirow[b]{2}{*}{$\begin{array}{c}\text { Percentage } \\
\text { Correct }\end{array}$} \\
\hline & & & \multicolumn{2}{|c|}{$\begin{array}{c}\text { Doctor patient communication } \\
\text { among HIV/AIDS patients }\end{array}$} & \\
\hline & & & Not Effective & Effective & \\
\hline \multirow{4}{*}{ Step 0} & Doctor patient & Not & 0 & 93 & .0 \\
\hline & communication among & Effective & & & \\
\hline & HIV/AIDS patients & Effective & 0 & 269 & 100.0 \\
\hline & \multicolumn{2}{|l|}{ Overall Percentage } & & & 74.3 \\
\hline
\end{tabular}

b. The cut value is .500

Variables in the Equation for Critical health literacy

\begin{tabular}{|c|c|c|c|c|c|c|c|}
\hline & & B & S.E. & Wald & df & Sig. & $\overline{\operatorname{Exp}(B)}$ \\
\hline Step 0 & Constant & 1.06194 & .117 & 82.149 & 1 & .000 & 2.892 \\
\hline
\end{tabular}

Further results shown in Block 1 table 6 below illustrate that there was a significant relationship between the dependent variable (doctor patient communication among HIV/AIDS patients) and the independent variable, critical health literacy with $\mathrm{p}=0.000$. The two pseudo $\mathrm{R}^{2}$ (Cox \& Snell R-Square and Nagelkerke R-square) values of 0.270 to 0.397 for model 1 and 0.314 to 0.461 for model 2 further suggested that $27.0 \%$ to $39.7 \%$ and $31.4 \%$ to $46.1 \%$ of the variation in doctor patient communication among HIV/AIDS patients in Homa Bay county was explained by critical health literacy for the model in block 1 in the absence of moderator and in the Block 1: Method = Enter presence of moderator respectively as illustrated in table 6 below.

Compared to the block 0 results, the inclusion of predictor variable in Block 1 increased the classification rate by $1.7 \%$ to $75.8 \%$ for model 1 (absent of moderator) and $6.9 \%$ to $81.2 \%$ that 81.2 in the presence of a moderator. The model with the moderator (demographic factors) again proved to be a better model than the model without a moderator (model 1), as was the case with the other two previous objectives. 
Table 6: Omnibus Tests of Model Coefficients for Critical health literacy

\begin{tabular}{|c|c|c|c|c|c|}
\hline \multicolumn{6}{|c|}{ Model 1 (Absence of Moderator) } \\
\hline & & & Chi-square & df & Sig. \\
\hline \multirow{3}{*}{ Step 1} & Step & & 120.720 & 1 & .000 \\
\hline & Block & & 120.720 & 1 & .000 \\
\hline & Model & & 120.720 & 1 & .000 \\
\hline \multicolumn{6}{|c|}{ Model 2 (Presence of Moderator) } \\
\hline & & & Chi-square & df & Sig. \\
\hline \multirow{3}{*}{ Step 1} & Step & & 144.239 & 2 & .000 \\
\hline & Block & & 144.239 & 2 & .000 \\
\hline & Model & & 144.239 & 2 & .000 \\
\hline \multicolumn{6}{|c|}{ Model Summary for Critical health literacy } \\
\hline \multicolumn{2}{|l|}{$\overline{\text { Step }}$} & -2 Log likelihood & Cox \& Sn & & Nagelkerke R Square \\
\hline \multicolumn{2}{|l|}{1} & $317.024^{\mathrm{a}}$ & \multicolumn{2}{|c|}{.270} & .397 \\
\hline \multicolumn{2}{|l|}{2} & $293.505^{\mathrm{a}}$ & \multicolumn{2}{|c|}{.314} & .461 \\
\hline
\end{tabular}

Table 0.7 Classification Table 2 for Critical Health Literacy

\section{Model 1 Without moderator}

\begin{tabular}{|c|c|c|c|c|c|}
\hline & \multirow[t]{3}{*}{ Observed } & & & Predicted & \multirow[b]{2}{*}{$\begin{array}{c}\text { Percentage } \\
\text { Correct } \\
\end{array}$} \\
\hline & & & \multicolumn{2}{|c|}{$\begin{array}{l}\text { Doctor patient communication } \\
\text { among HIV/AIDS patients }\end{array}$} & \\
\hline & & & Not Effective & Effective & \\
\hline \multirow{4}{*}{ Step 0} & Doctor patient & Not & 21 & 72 & 22.5 \\
\hline & communication among & Effective & & & \\
\hline & HIV/AIDS patients & Effective & 15 & 254 & 94.4 \\
\hline & \multicolumn{2}{|l|}{ Overall Percentage } & & & 76.0 \\
\hline \multicolumn{5}{|c|}{ a. Constant is included in the model. } & \\
\hline
\end{tabular}

Model 2 With moderator

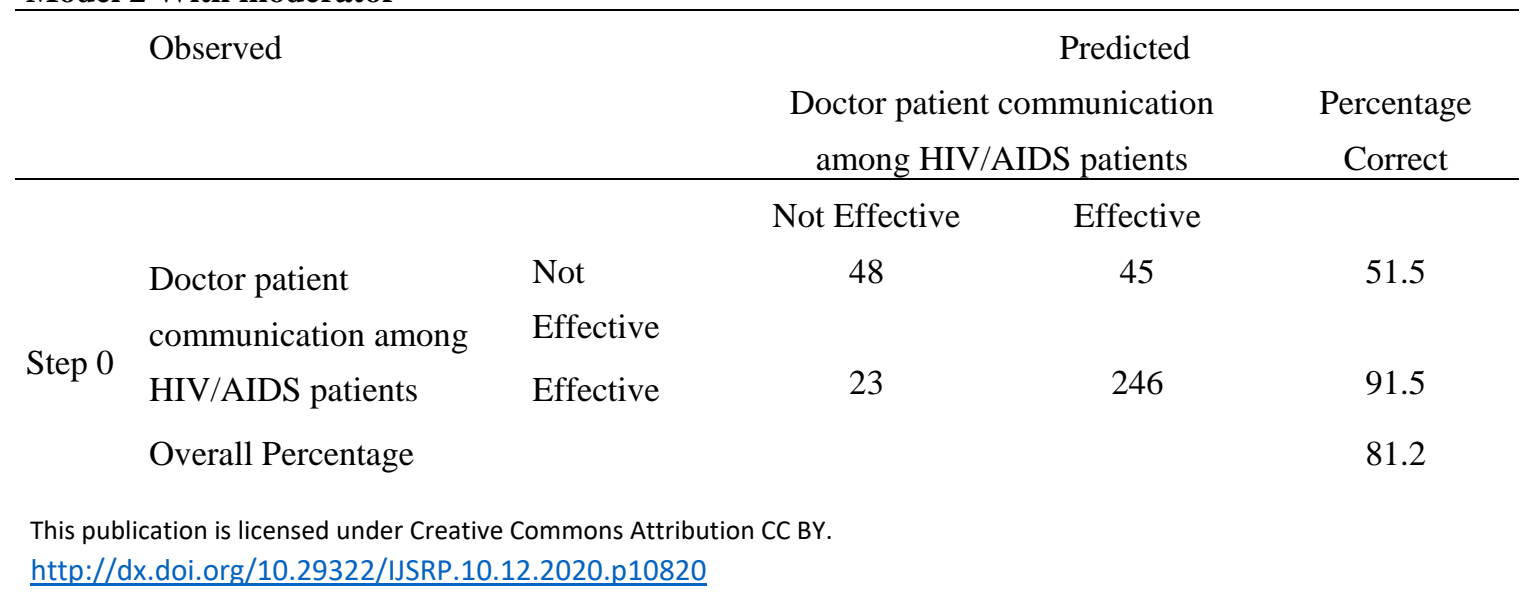


a. Constant is included in the model.

b. The cut value is .500

Table 8: Variables in the Equation

Model 2 Without moderator

\begin{tabular}{|c|c|c|c|c|c|c|c|}
\hline & & B & S.E. & Wald & df & Sig. & $\operatorname{Exp}(\mathrm{B})$ \\
\hline \multirow{2}{*}{ Step $1^{\mathrm{a}}$} & Critical health literacy & 2.501 & .366 & 46.642 & 1 & .000 & 12.198 \\
\hline & Constant & -6.254 & 1.042 & 36.062 & 1 & .000 & .002 \\
\hline
\end{tabular}

a. Variable(s) entered on step 1: $\mathrm{X}_{4}$.

Model 1 With moderator

\begin{tabular}{lllrrrrr}
\hline & & B & S.E. & Wald & df & Sig. & Exp(B) \\
\hline & Critical health literacy & 1.306 & .464 & 20.436 & 1 & .005 & 1.358 \\
\multirow{2}{*}{ Step $1^{\mathrm{a}}$} & $\begin{array}{l}\text { Critical health literacy } \\
\text { Z }\end{array}$ & 2.707 & .581 & 21.678 & 1 & .000 & 14.987 \\
& Constant & -7.982 & 1.009 & 62.602 & 1 & .000 & .000 \\
\hline
\end{tabular}

a. Variable(s) entered on step 1: Critical health literacy, Critical health literacy $* \mathrm{Z}$.

Table 9: Hosmer and Lemeshow Test

\begin{tabular}{llccc}
\hline Model1 Without moderator & Step & Chi-square & df & Sig. \\
& 1 & 8.164 & 8 & .418 \\
Model 2 With moderator & Step & Chi-square & df & Sig. \\
& 1 & 3.348 & 8 & .911 \\
\hline
\end{tabular}

As described by Nutbean (5), critical health literacy as very advanced cognitive abilities that, in combination with social skills, can be utilized to examine information critically and to use this information to gain greater control over life occasions and circumstances. Patients with adequate critical health literacy skills are characterized by the self-confidence to act independently on advice and interact successfully with the health care system and providers. This could explain why this study found a significant positive relationship between critical health literacy and doctor patient communication, similar to other studies comparing health literacy to various health outcomes $(17,19)$.

Previous studies have found varied results concerning which health literacy domain has the greatest influence on health outcomes. The study by Heijmans et al. (17), for example, concluded that communicative health literacy had the strongest correlations with all health outcome measures, followed by critical health literacy and functional health literacy. However, this study found critical health literacy as, by far, superior to the two other domains of health literacy. The variation could partly be due to different health literacy scales currently in use, coupled with the fact most of these other studies involved mainly hypertensive and diabetic patients. Further, well organized HIV/IDS support group networks and high concentration of civil societies and NGOs operating in Homa Bay county may be credited with empowering the patients to advocate for their health.

\section{Conclusions}

Inferential statistics revealed that critical health literacy had a significant positive influence on doctor patient communication among HIV/AIDS patients in Homa Bay county. Critical health literacy is more advanced cognitive skills that, together with social skills, can be applied to critically analyze health information and use this information to exert greater control over life events and situations. It implies acting as a person or a group to improve health through the political framework or social activism. Well organized HIV/IDS support group networks and high concentration of civil societies and NGOs operating in Homa Bay county may be credited with empowering the patients to advocate for their health. Such networks, should be encourages and their actions scaled up. 


\section{References}

1. Van den Broucke, S. (2016). Health literacy: a critical concept for public health. Archives of Public Health. https://doi.org/10.1186/2049-3258-72-10

2. Kobayashi, L. C. (2016). Health Literacy During Ageing and Implications for Health Behaviour.

3. US Department of Health \& Human Services. (2009). Fact Sheet: Health Literacy Basics. Health Promotion.

4. Farmanova, E., Bonneville, L., \& Bouchard, L. (2018). Organizational Health Literacy: Review of Theories, Frameworks, Guides, and Implementation Issues. Inquiry : A Journal of Medical Care Organization, Provision and Financing, 55. https://doi.org/10.1177/0046958018757848

5. Nutbeam, D. (2009). Defining and measuring health literacy: What can we learn from literacy studies? International Journal of Public Health, 54(5), 303305. doi:10.1007/s00038-009-0050-x

6. Schillinger, D., Grumbach, K., Piette, J., Wang, F., Osmond, D., Daher, C., ... Bindman, A. B. (2002). Health Literacy With Diabetes Outcomes. Jama, 288(4), 475-482.

7. Geboers, B. (2017). Understanding the role of health literacy in self-management and health behaviors among older adults.

8. Liu, H., Zeng, H., Shen, Y., Zhang, F., Sharma, M., Lai, W., ... Zhao, Y. (2018). Assessment tools for health literacy among the general population: A systematic review. International Journal of Environmental Research and Public Health, 15(8). https://doi.org/10.3390/ijerph15081711

9. Rademakers, J., \& Heijmans, M. (2018). Beyond reading and understanding: Health literacy as the capacity to act. International Journal of

Environmental

10. Herndon, J. B., Chaney, M., \& Carden, D. (2011). Health literacy and emergency department outcomes: A systematic review. Annals of Emergency Medicine, 57(4), 334-345. https://doi.org/10.1016/j.annemergmed.2010.08.035

11. Disler, R., Glenister, K., \& Wright, J. (2020). Rural chronic disease research patterns in the United Kingdom, United States, Canada, Australia and New Zealand: A systematic integrative review. $B M C$ Public Health, 20(1). doi:10.1186/s12889-020-
08912-1

12. Kripalani, S., Jacobson, T. A., \& Mugalla, C. I. (2012). NIH Public Access, 5(5), 269-275. https://doi.org/10.1002/jhm.667.HealthIshikawa, H., Takeuchi, T., \& Yano, E. (2008). Health literacy scales. PsycTESTS Dataset. doi:10.1037/t17922-000

13. Persell, S. D., Osborn, C. Y., Richard, R., Skripkauskas, S., \& Wolf, M. S. (2007). Limited health literacy is a barrier to medication reconciliation in ambulatory care. Journal of General Internal Medicine, 22(11), 1523-1526. https://doi.org/10.1007/s11606-007-0334-x

14. Sim, D., Yuan, S. E., \& Yun, J. H. (2016). Health literacy and physician-patient communication : a review of the literature. The International Journal of Communication and Health, 10(1), 101-114.

15. Ishikawa, H., Takeuchi, T., \& Yano, E. (2008). Health literacy scales. PsycTESTS Dataset. doi:10.1037/t17922-000

16. National AIDS Control Council (NACC), K., National Aids Control Council, \& Ministry of Health. (2018). Kenya HIV County Profiles 2016. NACC, Ministry of Health, Government of Kenya., 150. https://doi.org/10.1017/CBO978110741532

17. Heijmans, M., Waverijn, G., Rademakers, J., Van der Vaart, R., \& Rijken, M. (2015). Functional, communicative and critical health literacy of chronic disease patients and their importance for selfmanagement. Patient Education and Counseling, 98(1), 41-48. https://doi.org/10.1016/j.pec.2014.10.006

18. Harris, K., Jacobs, G., \& Reeder, J. (2019). Health systems and adult basic education: A critical partnership in supporting digital health literacy. HLRP: Health Literacy Research and Practice, 3(3), S33-S36. https://doi.org/10.3928/2474830720190325-02

19. Fagbamigbe, A. F., Adebayo, S. B., \& Idemudia, E. (2016). Marital status and HIV prevalence among women in Nigeria: Ingredients for evidence-based programming. International Journal of Infectious Diseases, 48, 57-63. https://doi.org/10.1016/j.ijid.2016.05.002 